\title{
ESTUDO DE ANTECEDENTES PROJETUAIS PARA A IMPLANTAÇÃO DE CENTRO DE CULTURA, ESPORTE E LAZER NA ANTIGA AARP EM PIRAPOZINHO - SP
}

\author{
Korina Costa, Sidielen Carmen Souza Sobrinho. \\ Universidade do Oeste Paulista - UNOESTE, Faculdade de Engenharias e Arquitetura e Urbanismo, \\ Presidente Prudente, SP.E-mail: korina.arq@gmail.com, sidielensobrinho@outlook.com.
}

\section{RESUMO}

Nos últimos anos no Brasil, o interesse por centro cultural teve um crescimento gigantesco financiado por investimentos e pelas leis de incentivo à cultura, sendo, atualmente, uma das principais realizações por parte dos órgãos públicos. Atualmente desativada, a Associação Atlética e Recreativa de Pirapozinho (AARP) foi um antigo clube recreativo da cidade de Pirapozinho - SP. Este artigo apresenta a análise de três antecedentes projetuais de arquitetura e urbanismo que possuem níveis diferenciados de envolvimento com a cultura, sendo eles: Sesc Pompeia, Centro Educamais Jacareí e Centro Cultural Thread; e lança diretrizes para o posterior projeto a ser implantado na antiga AARP. O principal objetivo do trabalho é analisar os antecedentes arquitetônicos e propor diretrizes para o novo de centro de cultura, esporte e lazer no local.

Palavras-chave: Associação Atlética e Recreativa de Pirapozinho, Sesc Pompeia, Centro Educamais Jacareí, Centro Cultural Thread, Diretrizes projetuais.

\section{DESIGN REFERENCES STUDY TO IMPLANTATION OF CULTURE CENTER, SPORT AND LEISURE ON THE FORMER AARP PIRAPOZINHO - SP}

\begin{abstract}
In Brazil, the last few years, interest in cultural center had a huge growth supported by investments and laws to encourage culture, being currently one of the major achievements by public authorities. Currently disabled, the Associação Atlética e Recreativa de Pirapozinho (AARP) was a former recreational club in Pirapozinho, São Paulo state, Brazil. This article presents the analysis of three design references of architecture and urbanism that have different levels of engagement with culture, as follows: Sesc Pompeia, Centro Educamais Jacareí and Thread Cultural Center; and launches guidelines for the later project to be implemented in former AARP. The main objective of the study is to analyze the design references and propose guidelines for the new center of culture, sports and leisure at the place.
\end{abstract}

Keywords: Associação Atlética e Recreativa de Pirapozinho, Sesc Pompeia, Centro Educamais Jacareí, Thread Cultural Center, Project guidelines. 


\section{INTRODUÇÃO}

Fundada na década de 1960, a Associação Atlética e Recreativa de Pirapozinho (AARP) foi uma empresa privada que atuava na área de clubes recreativos e esportivos. Desativado desde os anos 2000, o edifício localizado no centro da cidade de Pirapozinho, sofre com a degradação física e de sua memória desde então. $O$ desrespeito com sua preservação incita o descaso pelo patrimônio histórico e cultural do município e fere a memória da cidade. Tendo em vista o abandono envolvendo o edifício da AARP, somado com o apelo cultural e recreativo que espaço possui e ao fato de sua implantação ser em um local privilegiado, com fácil a acesso por vários pontos da cidade, justifica-se a implantação de um centro de cultura na área, tendo em vista que existe uma carência de espaços de socialização em Pirapozinho.

Desta forma, os antecedentes arquitetônicos aqui analisados incorporam questões relativas à espaços culturais, são eles: Sesc Pompeia da arquiteta Lina Bo Bardi, Centro de Formação de Professores Educamais Jacareí de Ruy Ohtake e Centro Cultural Thread, da arquiteta Toshiko Mori.

O objetivo deste estudo é entender como funcionam tais espaços culturais, analisar as características projetuais para criar uma base conceitual e dar diretrizes para a implantação de um centro de cultura, esporte e lazer na antiga AARP.

\section{METODOLOGIA}

A presente pesquisa é de cunho qualitativo e foi desenvolvida por meio de investigação bibliográfica, estudo imagético, levantamento documental, análise de referenciais arquitetônicos e levantamentos in loco, para levantar as condições da obra em estudo, feito segundo os apontamentos de Teixeira (2000), que direciona também para que a pesquisa se desenvolva pautada pela correlação entre dados levantados e sua compreensão e análise, conforme observação do investigador.

\section{RESULTADOS}

Para o desenvolvimento conceitual do projeto foram escolhidos três antecedentes arquitetônicos da seguinte maneira: Sesc Pompeia (Lina Bo Bardi) - pelo trabalho com a preexistência e pelo programa de necessidades bastante expansivo -, Centro Educamais Jacareí (Ruy Ohtake) - pelo apelo cultural e pela arquitetura chamativa que faz com a obra se torne um marco na paisagem - e Centro Cultural Thread (Toshiko Mori) - pela preocupação com a necessidades dos usuários e a preocupação em se adequar com o local e o entorno.

\section{SESC POMPEIA}

O Centro de Lazer da Fábrica Pompeia - SESC Pompeia -, fica localizado no bairro da Pompeia, antigo bairro industrial da zona oeste da cidade de São Paulo. O centro foi projetado pela arquiteta italiana Lina Bo Bardi, numa área onde situava-se uma antiga fábrica de tambores. A obra começou em 1977 e durou nove anos. A primeira etapa (que compreendia o centro onde funcionava a antiga fábrica) foi inaugurada em 1982 e em 1986 o bloco esportivo foi aberto ao público. (SESC SP, 2016).

Segundo Ferraz (2008), quando Lina Bo Bardi chegou ao conjunto para iniciar os trabalhos o SESC já promovia atividades culturais e esportivas naquele espaço de forma improvisada. Lina, captando a essência do lugar, quis apenas manter e amplificar tais atividades. A arquiteta optou por manter a implantação horizontal já existente, anexando a ela uma estrutura vertical.

A parte nova do conjunto Pompéia é composta por três volumes prismáticos de concreto: dois prismas retangulares e um cilindro. Tais sólidos prismáticos estão dispostos de modo que, juntos, caracterize uma unidade fabril. 
O prisma maior contém cinco pavimentos e possui perimetrais e portantes, não possuindo nenhuma estrutura interna complementar (FRACALOSSI, 2013). Nele estão localizados o ginásio, as quadras, piscinas. Interligado por passarelas de concreto está o prisma retangular menor, onde acontece toda a circulação vertical da nova unidade. São três passarelas simétricas e uma superior assimétrica. Esse prisma localiza-se girado trinta e três graus horários em relação ao prisma maior e é ele que abriga toda a circulação: dois elevadores, uma escada caracol em seu interior e a escada de segurança externa. (OLIVEIRA, 2007).

Sob as passarelas de concreto há um córrego canalizado - o Córrego das Águas Pretas - que cria uma área non edificandi (FRACALOSSI, 2013). Nesta área, foi construído um deque de madeira, que é utilizado como solarium e também como espaço para eventuais shows.

O último prisma que compõe o conjunto une-se ao prisma retangular menor através de uma passarela metálica que parte da sua cobertura. (FRACALOSSI, 2013). Segundo Oliveira (2007), no início das obras a chaminé original da fábrica se encontrava destruída e não se justificava reconstituí-la, por isso, a torre cilíndrica, projetada para funcionar como a caixa d'água da Fábrica do SESC Pompeia, foi batizada como a sua nova chaminé.

Analisando a obra, percebe-se o grande empenho da arquiteta empregado na preservação da preexistência e de seu caráter tectônico. A horizontalidade dos antigos prédios se incorpora a malha preexistente e nela se dilui. Já os novos volumes, mesmo tendo sido verticalizados, dialogam com a essência histórica da obra e exploram a característica industrial.

Lina consegue sincronizar o programa de necessidades - dinâmico e coerente com as atividades já desenvolvidas de forma improvisadas no local antes da intervenção - com formas arquitetônicas e distribuição de espaços, gerando participação, interação e envolvimento dos usuários com a arquitetura proposta no SESC Pompeia. Esse envolvimento cria movimento e experimentação sensorial entre o usuário e a arquitetura, tornando-se o grande entretenimento do local.

\section{CENTRO DE FORMAÇÃO DE PROFESSORES EDUCAMAIS JACAREÍ}

Implantado próximo à nova rodoviária da cidade, no trajeto entre a Rodovia Presidente Dutra e a cidade de Jacareí, o Centro de Formação de Professores EducaMais Jacareí é um projeto do arquiteto Ruy Ohtake, e possui $6,7 \mathrm{mil} \mathrm{m}^{2}$ de área construída, em um terreno de 20 mil m² (VICTORIANO, 200-?).

O projeto é uma peça cultural de grande importância para a cidade e para o Vale do Paraíba, por isso precisava ser chamativo. $\mathrm{O}$ grande destaque da obra é a organicidade da forma. De acordo com Zevi (1945), a arquitetura orgânica busca em seus espaços a felicidade material e psicológica e espiritual do homem. Tal definição se aplica a obra de Ruy Ohtake, uma vez que é através da forma que o arquiteto busca expressar a cultura embutida no edifício. A forma é orgânica e sua função também, pois, mesmo com seu caráter monumental, possui uma postura integradora, movimentada e dinâmica, coerente com as atividades propostas para o local e com as necessidades dos usuários.

Segundo Ching (2013), a cor afeta o peso de uma forma, "ela é o atributo que mais claramente distingue uma forma de seu ambiente" (CHING, 2013, p. 34). Nesta a obra, além da forma diferenciada, a fachada foi pintada com quatro tons de vermelho, transformando a construção em um marco na paisagem.

A obra se organiza em três pavimentos, com um programa de necessidades que abrange: auditório, espaços expositivos, salas de multiuso, lanchonete, sala de música, refeitório etc. Complementando o prédio principal, o Ruy Ohtake também projetou uma creche, brinquedoteca, setores recreativos e de atividades para a terceira idade, parte dos quais utiliza espaços abertos; posicionados, através do jardim, em patamares acomodados à topografia. Esses 
espaços oferecem versatilidade, configurando-se como uma grande fábrica de atividades para diferentes faixas etárias.

O térreo é acessado por uma galeria que leva ao auditório e ao espaço de exposição que, por sua vez, distribui o fluxo dos outros pavimentos. O espaço de exposições possui pé direito duplo e é ladeado por salas de multiuso. O eixo focal do espaço de exposições é pontuado por uma cobertura translúcida central com perfil arredondado de onde pendem esculturas tubulares que funcionam como prolongamentos não estruturais dos tubos de sustentação das telhas (ARCOWEB, 200-?). Tal cobertura, valoriza a entrada de luz solar e, aliada ao pé-direito duplo, garante boa distribuição de iluminação ao ambiente, além de favorece-lo esteticamente.

O pavimento inferior possui sala de música, almoxarifado, refeitório e um espaço de exposições. O espaço de exposições leva a parte externa do terreno através de aberturas na fachada posterior que se abre para a paisagem verde do entorno. Esta fachada tem efeito de insolação oeste que é negativo para o aquecimento dos interiores, por isso, em sobreposição à fachada, foi feita uma pele de grelha metálica que ameniza a temperatura. Esse brise tem figura sinuosa, resultando faixas transparentes junto ao piso e ao teto, entremeadas à luz filtrada pela grelha (ARCOWEB, 200-?).

Através da análise da obra, percebe-se o compromisso de Ruy Ohtake em fazer com que o edifício se tornasse um grande marco na paisagem local. As soluções projetuais - cor, forma e tamanho - mostram o empenho do arquiteto em transformar a peça cultural em um ponto de referência para toda a cidade.

O Centro de Formação de Professores EducaMais Jacareí é uma obra de muita coesão e fluidez que, através de através de seu caráter monumental, consegue cumprir sua principal premissa: ser um grito enérgico de cultura.

\section{CENTRO CULTURAL THREAD}

Localizado em Sinthian, uma vila rural em Tambacounda, na região sudeste do Senegal, o Thread é uma inovadora construção ecológica que combina materiais e costumes locais com design e geometria inovadora. (RANGEL, 2015).

Em tons de areia, o novo projeto da arquiteta de origem japonesa Toshiko Mori é exemplo de compreensão das necessidades dos usuários e de combinação entre tecnologia avançada, mão de obra artesanal e materiais locais além de exibir excelente integração com a paisagem (FERRAZ, 2015). O edifício é uma obra de arte em si. O telhado curvo e dramático é inteiramente feito de palha de grama local e bambu, enquanto as paredes brancas simples foram construídas a partir de tijolos de barro feitos localmente e no coração do edifício abre-se para o céu. (ELLIS-PETERSEN, 2015)

Inaugurado em março de 2015, o centro é um local de encontro para feiras, educação, apresentações e reuniões que dá ao povo de Sinthian e da região uma oportunidade de descobrir novas formas de criatividade e cultivar suas habilidades através de uma variada programação ao lado das residências dos artistas ao lado. O centro é um espaço para a comunidade local e um lugar onde os artistas residentes podem ter uma experiência verdadeiramente significativa da sociedade Sinthian. (MORI, 2015).

Analisando a obra vê-se que sua execução é resultado da adequação de técnicas locais e dos recursos disponíveis com um desenho novo e expressivo, que consegue, ao mesmo tempo, se integrar a paisagem se tornar uma referência para o local. Toshiko Mori soube racionalizar de forma eficiente os materiais e a mão de obra disponíveis criando um ícone para a arquitetura senegalesa, além de dar visibilidade internacional para o pequeno vilarejo de Sinthian e exaltar a cultura local.

Através da cobertura projetada em palha, Mori cria uma grande proteção do sol e da chuva para a edificação e aproveita para desenvolver um sistema de captação e armazenagem de 
água tornando o edifício eficiente. Sob o telhado, se distribuem os ambientes do conjunto com fechamentos feitos com peças vazadas confeccionadas em barro, que permitem a passagem do vento: solução projetual para o conforto do ambiente.

A modéstia da arquitetura de Mori se transforma em genialidade, transformando o edifício e toda a paisagem local em um marco e, ao mesmo tempo, oferecendo um refúgio cultural para todo o vilarejo.

\section{DISCUSSÃO}

A exemplo do Sesc Pompeia de Lina Bo Bardi, o projeto de implantação irá trabalhar a relação e respeito pela preexistência, buscando fluidez e explorando a relação do usuário com o próprio corpo, produzindo movimento e fazendo com que a obra em si, já seja uma forma de entretenimento para a população.

Conforme o projeto do Centro EducaMais de Ruy Ohtake, aspectos de concepção formal serão considerados, o projeto irá buscar um diferencial na forma buscando fazer com que a obra se torne um ponto de referência para toda a cidade. Ainda em relação ao Centro EducaMais o projeto deverá manter fluidez entres as áreas internas e externas.

Considerando o Centro Cultural Thread de Toshiko Mori, a compreensão das necessidades dos usuários é o que mais influir neste projeto, assim como também a forma da cobertura diferenciada. Desta forma, o projeto irá explorar o uso já desenvolvido atualmente no local, proporcionando espaços dinâmicos para o público alternativo já existente no local, além de criar outros espaços convidativos para atrair outras parcelas da população.

\section{CONCLUSÃO}

O interesse maior na análise de tais projetos - SESC Pompeia de Lina Boa Bardi, Centro de Formação de Professores Educamais Jacareí de Ruy Ohtake e Centro Cultural Thred de Toshiko Mori - se dá pelo fato de que, mesmo desenvolvendo atividade parecidas, as obras são formalmente diferentes e cada uma, à sua maneira, consegue executar seus objetivos pragmáticos de forma notável.

Quando analisados os aspectos de eficiência, todas as obras conseguiram resolver fatores como implantação, partido formal, programa de necessidades, funcionalidade, acessos, circulação, forma, textura, cor, dimensão e estrutura, para que o projeto apresentasse o melhor desempenho. Assim, os estudos aqui feitos não se preocupa em qualificar um ou outro projeto como melhor, mas sim em apontar as diferenças ou semelhanças nas disposições físicas e espaciais, identificando conteúdos e reconhecendo as visões de projetos de diferentes contextos.

Acredita-se que a maior contribuição deste trabalho é a associação das informações no que diz respeito a análises de referenciais arquitetônicos, buscando a implantação de um centro de cultura na cidade de Pirapozinho.

\section{REFERÊNCIAS}

ARCO WEB. Ruy Ohtake Arquitetura e Urbanismo: Centro cultural, Jacareí, SP. Disponível em: $<$ https://arcoweb.com.br/projetodesign/arquitetura/ruy-ohtake-arquitetura-urbanismo-centrocultural-jacarei-sp> Acesso em 26 mar. 2016.

CHING, F. Arquitetura: forma, espaço e ordem. 3. ed. São Paulo: Bookman, 2013.

ELLIS-PETERSEN, H. Parched backwater in Senegal where local traditions and modern art collide. The Guardian, 202 mar. 2015. Disponível em: < http://www.theguardian.com/world/2015/mar/20/thread-centre-senegal-where-local-traditionsand-modern-art-collide> Acesso em 8 abr. 2016 
FERRAZ, M. Numa velha fábrica de tambores. SESC-Pompéia comemora 25 anos. Minha Cidade, São Paulo, ano 08, n. 093.01, Vitruvius, abr. 2008. Disponível em: <http://www.vitruvius.com.br/revistas/read/minhacidade/08.093/1897>. Acesso em: $10 \mathrm{mar}$. 2016.

FERRAZ, M. S. Projeto de Toshiko Mori no Senegal mostra por que áreas rurais e afastadas ou regiões pouco conhecidas não devem ser desprezadas como potenciais de inovação. Bamboo, 5 mar. 2015. Disponível em: < http://bamboonet.com.br/posts/projeto-de-toshiko-mori-no-senegalmostra-por-que-areas-rurais-e-afastadas-de-regioes-pouco-conhecidas-nao-devem-serdesprezadas-como-potenciais-de-inovacao-1> Acesso em 7 abr. 2016.

FRACALOSSI, I. Clássicos da Arquitetura: SESC Pompéia / Lina Bo Bardi. ArchDaily Brasil, 05 nov. 2013. Disponível em: <http://www.archdaily.com.br/153205/classicos-da-arquitetura-sescpompeia-slash-lina-bo-bardi> Acesso em: 12 mar. 2016.

MORI, T. Residência do Novo Artista em Senegal. Traduzido por Maria Julia Martins. 7 jun. 2015. Disponível em: < http://www.archdaily.com.br/br/767885/residencia-do-novo-artista-em-senegaltoshiko-mori> Acesso em: 6 abr. 2016.

RANGEL, J. Thread - Inovadora construção ecológica no Senegal. Rio de Janeiro, 23 jun. 2015. Disponível em: < http://sustentarqui.com.br/construcao/thread-inovadora-construcao-ecologicano-senegal/> Acesso em: 7abr. 2016.

SESC SP. SESC Pompeia. "Sobre a unidade". 2016. Disponível em: <www.sescsp.org.br/unidades/11_POMPEIA/\#/content=tudo-sobre-a-unidade>. Acesso em: 21 mar. 2016.

TEIXEIRA, E. As três metodologias. 2a ed. São Paulo: Vozes, 2000.

VICTORIANO, G. Marco na paisagem. Disponível em: <http://www.galeriadaarquitetura.com.br/projeto/ruy-ohtake_centro-de-formacao-deprofessores-educamais-jacarei/1920> Acesso em 26 mar. 2016.

ZEVI, B. Arquitetura Orgânica. Verso un' architettura organica, Torino, Enaudi, 1945, pp. 63, 71-75. Disponível em: http://www.fau.usp.br/cursos/graduacao/arq_urbanismo/disciplinas/auh0313/Zevi_1945.pdf> Acesso em: 30 mar. 2016. 